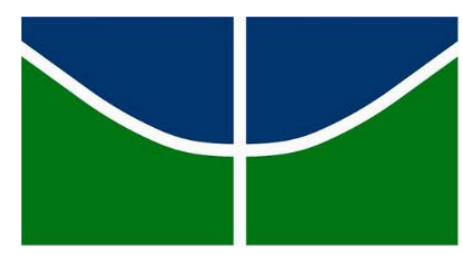

UNIVERSIDADE DE BRASÍLIA

Faculdade de Tecnologia

Departamento de Engenharia Florestal

Fernanda Palhares Silva

CARACTERÍSTICAS MORFOLÓGICAS DAS FIBRAS DE Agave americana l., Saccharum spp., Heliconia rostrata, Arundo donax, Musa spp. E ROSETA DE Ananas comosus VISANDO A PRODUÇÃO DE PAPEL ARTESANAL

Brasília - DF, 2017 


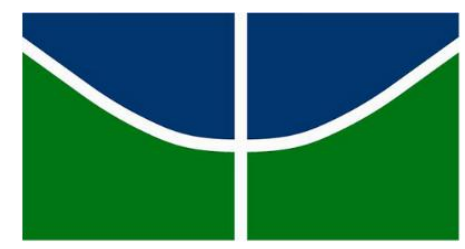

UNIVERSIDADE DE BRASÍLIA

Faculdade de Tecnologia

Departamento de Engenharia Florestal

CARACTERÍSTICAS MORFOLÓGICAS DAS FIBRAS DE Agave americana l., Saccharum spp., Heliconia rostrata, Arundo donax, Musa spp. E ROSETA DE Ananas comosus VISANDO A PRODUÇÃO DE PAPEL ARTESANAL

\author{
Aluna: Fernanda Palhares Silva \\ Orientador: Joaquim Carlos Gonçalez \\ Co-Orientadora: Thérèse Hofmann Gatti Rodrigues da Costa
}

Projeto de pesquisa a ser apresentado ao departamento de Engenheira Florestal da Universidade de Brasília, como parte das exigências para obtenção do título de Engenheira Florestal

Brasília - DF, 2017 


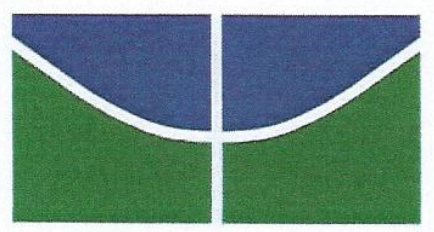

UNIVERSIDADE DE BRASÍLIA

Faculdade de Tecnologia

Departamento de Engenharia Florestal

\section{CARACTERÍSTICAS MORFOLÓGICAS DAS FIBRAS DE Agave americana l., Saccharum spp., Heliconia rostrata, Arundo donax e Musa spp. E ROSETA DE Ananas comosus VISANDO A PRODUÇÃO DE PAPEL ARTESANAL}

Estudante: Fernanda Palhares Silva

Matrícula: $12 / 0117436$

Orientador: Prof. Dr. Joaquim Carlos Gonçalez

Menção:

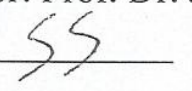

Prof. Dr. Joaquim cà los Gonçalez

Universidade de Brasília - UnB

Departamento de Engenharia Florestah

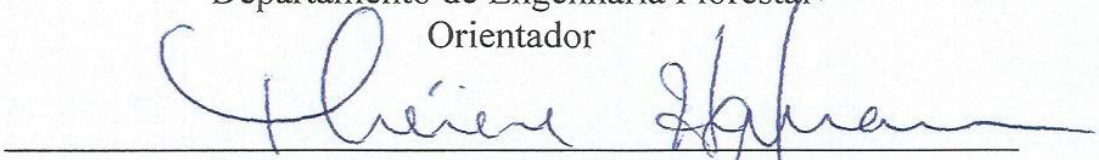

Prof. Dr. Thérèse Hofmann Gatti Rodrigues da Costa

Universidade de Brasília - UnB

Co-orientadora/Examinador Intern $\varnothing$

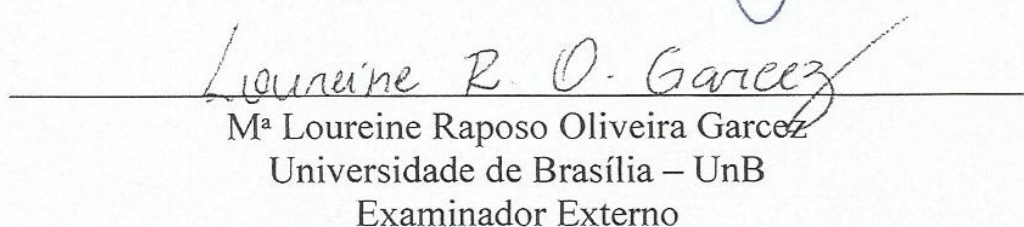

Examinador Externo 


\section{AGRADECIMENTOS}

Em especial à minha família que sempre esteve ao meu lado, me apoiando e fazendo do possível ao impossível para que eu pudesse ter um ensino de qualidade e me tornasse uma profissional exemplar, sempre zelando pelos meus estudos e me proporcionando as melhores oportunidades, além de todos os ensinamentos diários de como ser uma pessoa ética e correta. Ao meu namorado Thales que esteve comigo desde o início me incentivando a e acreditando no meu potencial.

Agradeço à Loyane e a Miriam do Laboratório de Tecnologia da Madeira do Departamento de Engenharia Florestal por me auxiliarem durante as pesagens e em todo o tempo que as amostras precisaram ficar na estufa, me dando suporte e atenção. Ao laboratório de anatomia vegetal do Instituto de Biologia da Universidade de Brasília por ceder o espaço e os materiais necessários para as análises vegetais, em especial à professora Julia e aos estagiários Débora e Thiago.

Ao professor Joaquim Gonçalez que me orientou durante esse último ano, na realização desse trabalho dedicando seu tempo e atenção. A todos os meus professores pelo conhecimento passado e a todas as pessoas que me ajudaram durante a minha graduação, incluindo funcionários de portaria, faxina e da secretaria.

A professora Thérèse por fornecer o insumo, conhecimento e ajuda necessária para o trabalho, a Loureine que sempre esteve disponível e disposta a ajudar com tudo que tive dificuldade, sempre me dando melhores alternativas do que fazer e conselhos para poder melhorar o trabalho.

Aos meus colegas de cursos Édipo, Arthur, Isabella, Sara, Luiza e Ana que compartilharam angustias e alegrias durante toda a minha graduação, pelos trabalhos feitos, histórias e saídas de campo juntos, em especial ao Willer que forneceu todas as informações necessárias para a minha pesquisa e sempre esteve disponível a ajudar com o que fosse preciso, e aos meus amigos Juliana, Fernanda e Pedro que, além de tudo, me acompanharam e ajudaram de perto nessa reta final de conclusão. 


\section{RESUMO}

Nos grandes centros urbanos do país existe um expressivo volume de consumo de papel, bem como de resíduos gerados pelo consumo de alimentos e cereais, porém muitas vezes esses resíduos não são aproveitados desperdiçando a possibilidade de um uso mais nobre, como a produção de papel. O objetivo deste trabalho é a caracterização morfológica de fibras de Agave americana l., Saccharum spp., Heliconia rostrata, Arundo donax, Musa spp. e roseta de Ananas comosus, visando a produção de papel artesanal. Foi realizada a individualização das fibras e montagem das laminas para análise. Posteriormente essas fibras foram medidas no microscópio com o auxílio de software de computador. Também foi determinada a densidade básica pelo método do máximo teor de umidade. A espécie Saccharum spp., classificada como fibra curta, apresentou melhores caraterísticas morfológicas. Já para a categoria de fibras longas, as fibras da espécie Musa spp., se destacaram sugerindo melhores características na produção polpa celulósica, sendo está a espécie que também se destacou com os melhores índices estudados dentre as seis analisadas. A confirmação da potencialidade ou não das espécies estudadas será confirmada com a produção da polpa e papel e análise de suas propriedades.

Palavras-Chave: Agave americana l., Saccharum spp., Heliconia rostrata, Arundo donax, Musa spp. e roseta de Ananas comosus, fibras, anatomia, densidade, potencialidade. 


\begin{abstract}
In the great urban centers of the country there is an expressive volume of consumption of paper, as well as waste generated by the consumption of waste and cereals, but often these wastes not used, wasting the possibility of nobler use, such as paper production. The objective of this work is the morphological characterization of Agave americana L., Saccharum spp., Heliconia rostrata, Arundo donax and Musa spp. and rosette of Ananas comosus, aiming the production of artisanal paper. It was carried out the individualization of the fibers and assembly of the sheets for analysis. Later these fibers were measured under the microscope with the aid of computer software. The basic density was also determined by the maximum moisture content method. The species Saccharum spp., classified as short fiber, presented better morphological characteristics. For the long fiber category, the fibers of Musa spp. were highlighted suggesting better characteristics in cellulosic pulp production, being the species that also stood out the best indexes studied among the six studied. Confirmation of the potentiality or not of the species will be confirmed by pulp and paper production and analysis of their properties.
\end{abstract}

Keywords: Agave americana l., Saccharum spp., Heliconia rostrata, Arundo donax, Musa spp. and Ananas comosus, fibers, anatomy, density, potentiality. 


\section{SUMÁRIO}

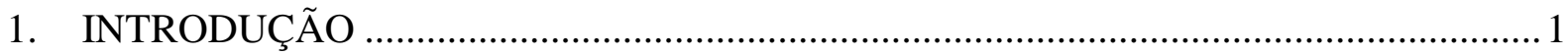

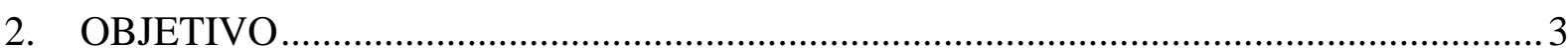

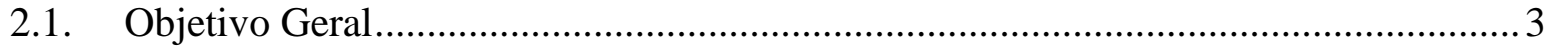

2.2. Objetivos Específicos .................................................................................

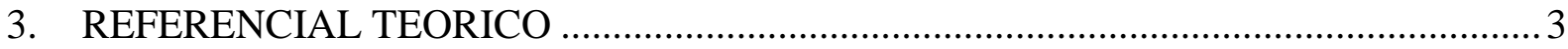

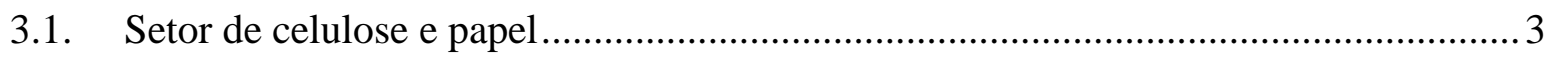

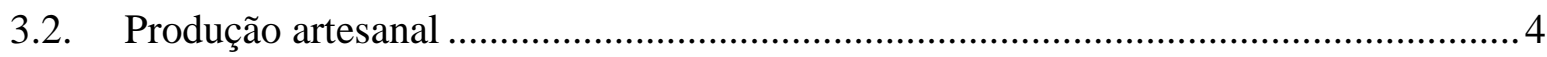

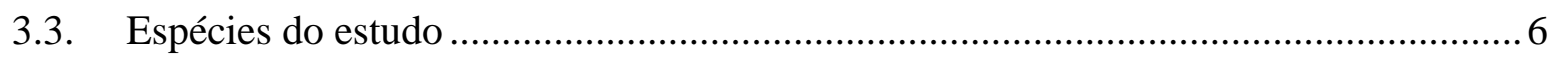

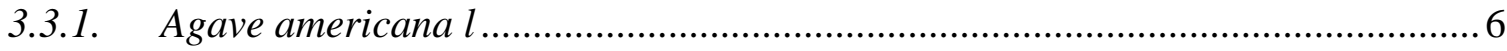

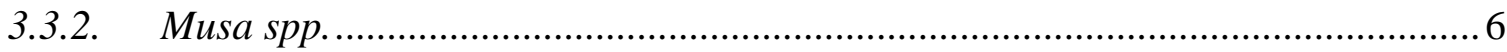

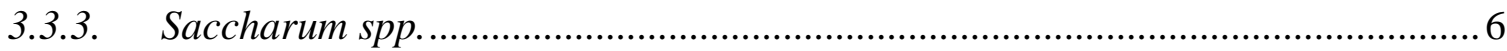

3.3.4. Heliconia rostrata …………………………………..............................

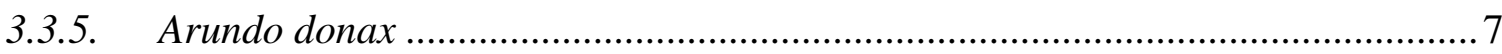

3.3.6. Ananas comosus, ...................................................................................

3.4. Caracterização Morfológica das Fibras ………………………………………..... 8

3.5. Correlações de fibras e índices associados ................................................................

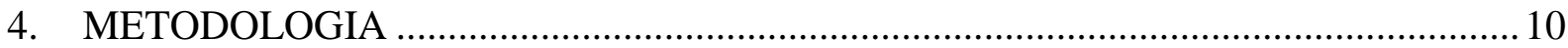

4.1. Material de estudo e Individualização das fibras ......................................................... 10

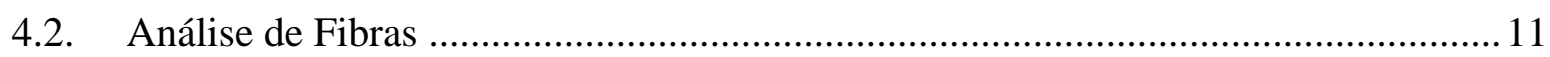

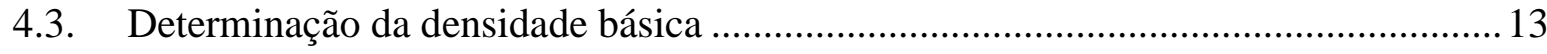

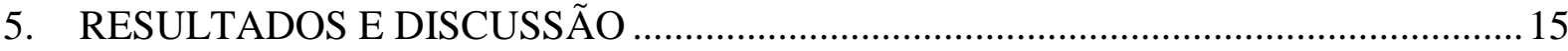

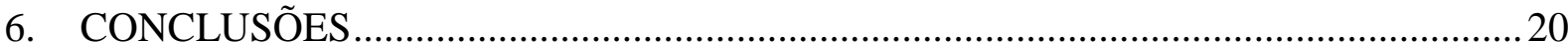

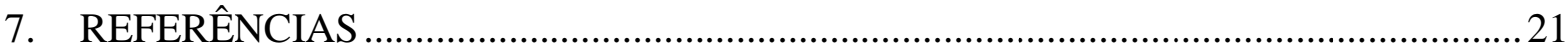




\section{LISTA DE FIGURAS}

Figura 1 - Individualização das fibras das seis espécies em estudo coradas com safranina... 11 Figura 2 - Mensuração das dimensões de comprimento, largura e diâmetro do lúmen através do software Image Pro Plus 6.0

Figura 3 - Preparação e padronização das amostras para submersão em água........................ 14

Figura 4 - Amostras das espécies seis espécies estudadas submersas em água...................... 14

Figura 5 - Amostras úmidas pesadas em balança de precisão............................................ 15

Figura 6 - Amostras sendo retiradas da estufa depois de completamente secas para posterior pesagem. 


\section{LISTA DE TABELAS}

Tabela 1 - Medidas descritivas das dimensões das fibras das seis espécies estudadas........... 16 Tabela 2 - Densidade básica média das seis espécies em estudo pelo método do máximo teor de umidade.

Tabela 3 - Dimensões médias e índices calculados comparando as seis espécies estudadas. 18 


\section{INTRODUÇÃO}

Desde épocas pré-históricas o homem se expressava através de símbolos e desenhos e, com o passar do tempo, o ser humano desenvolveu materiais mais refinados feitos a partir de peles e couros, barro cozido, cascas de árvores e outras fibras vegetais. Entretanto, foram os materiais desenvolvidos à partir de fibras vegetais que se consagraram como suporte para a escrita, devido a sua maior leveza e praticidade, apesar de sua menor resistência (TEIXEIRA, OLIVEIRA, GATTI E SUÁREZ, No prelo).

O papel surgiu por volta do ano 105 d.C. sendo o oficial da Corte Imperial Chinesa, T'sai Lun, o seu criador e pioneiro do processo de polpação. No Brasil o papel só foi introduzido pelos colonizadores no ano de 1809 (VIEIRA, 2011).

Segundo Klock (2013), com a revolução industrial e os avanços na produção de papel, a busca por novas matérias primas foi eminente, com isso a procura por características adequadas fez-se necessária, uma vez que nem todo vegetal apresenta condições e boas características para a fabricação de papel. Para que um vegetal tenha potencial para fabricação de papel, ele deve possuir características desejáveis como ser fibroso, estar disponível em grande quantidade o ano todo, ter baixo custo, fornecer ao produto final as características desejadas e ser facilmente renovável (KLOCK, ANDRADE, HERNANDEZ, 2013). Entre os vegetais, a madeira é a matéria prima que mais se aproxima das características desejáveis para essa finalidade.

As duas principais fontes de madeira utilizadas para produção de celulose no Brasil, são as florestas plantadas de Pinus e de Eucalyptus responsáveis por mais de 95\% do volume produzido. A celulose também pode ser obtida de outros tipos de plantas, não-madeiras, como bagaço de cana-de-açúcar, bambu, cachos de dendê e babaçu. Entretanto, o mercado de celulose de fibras alternativas ainda é bastante reduzido no Brasil. Ainda que muitos resíduos agroindustriais constituam mercados potenciais a serem explorados, para a grande maioria destes resíduos, não existem no Brasil iniciativas empresariais voltadas para a obtenção de fibras de celulose. Segundo a FAO (2013) citado por Souza et al. (2015), o Brasil produziu no ano de 2013, 165 mil toneladas de celulose de fibras alternativas (bambu - 127 mil toneladas, bagaço - 23 mil e outras fibras 15 mil toneladas).

A produção industrial de celulose com fibras alternativas, em escala comercial, ainda tem o custo muito elevado, quando se compara aos custos de produção de celulose provenientes da madeira. Por outro lado, pensando como uma opção social e ecológica, a 
utilização de fibras alternativas na produção de papel no segmento artesanal, parece-nos uma oportunidade muito interessante. A produção do papel artesanal não causa degradação ao meio ambiente, substitui materiais convencionais, o que reduz a utilização de recursos naturais e pode ser uma fonte de auto-sustentação para as comunidades.

Para produção de celulose, algumas variáveis estão envolvidas no processo. Em relação à matéria prima vegetal, a composição química e anatômica são fundamentais na qualidade e rendimento da celulose a ser obtida.

Para o processo industrial de produção de papel é necessária a separação da lignina e demais componentes menos abundantes da madeira, com a finalidade de obtenção dos carboidratos, principalmente a celulose e a hemicelulose. Este processo é conhecido como polpação, cujo o processo químico de produção de celulose não ultrapassa o rendimento de $60 \%$.

As características morfológicas das fibras também influenciam de maneira significativa nas propriedades desejadas para o papel, sendo utilizadas relações como o índice de Runkel que fornece informações de flexibilidade das fibras, o Coeficiente de Flexibilidade, que influencia na resistência ao estouro do papel, a Fração Parede e o Índice de Enfeltramento, que proporcionam informações de resistência (NISGOSKI et al. 2012). Para Foelkel e Barrichelo (1975) as relações de espessura, comprimento e largura das fibras determinam a qualidade do papel. Segundo os autores o comprimento das fibras está relacionado à resistência a tração e ao arrebentamento, enquanto a espessura da parede está relacionada de maneira positiva com o rendimento em produção de celulose.

Segundo Miranda (2008), a grande preocupação ambiental em relação ao setor de celulose e papel é que além de ser altamente dependente de recursos naturais como água e energia, também gera grandes níveis de ruídos, além da questão dos maciços de monocultura que causam perda na biodiversidade vegetal e animal.

O mercado de produção de papel com fibras alternativas, onde a celulose é obtida de outros tipos de plantas, não-madeireiras vem ganhando espaço ano a ano. Apesar de ser um mercado reduzido no Brasil, o setor de produção de celulose a partir de fibras alternativas aproveita grande parte dos resíduos agroindustriais, opção para driblar as questões ambientais no que tange à produção de celulose a partir de madeira. 


\section{OBJETIVO}

\subsection{Objetivo Geral}

O estudo tem por objetivo analisar as características morfológicas das fibras de seis espécies vegetais Agave americana l. (pita), Saccharum spp. (cana-de-açucar), Heliconia rostrata (bananeira do brejo), Arundo donax (cana do reino), Musa spp. (bananeira) e roseta de Ananas comosus (coroas de abacaxi), verificando seus potenciais de uso para a produção de papel artesanal.

Este estudo vem completar as análises iniciadas no relatório técnico interno desenvolvido no Laboratório de Materiais Expressivos (LEME) do Departamento de Artes Visuais da Universidade de Brasília (UnB) e do Laboratório de Materiais Combustíveis (LMC) do Instituto de Química da UnB sobre o estudo dos efluentes e das polpas celulósicas utilizadas na produção de papel artesanal das 6 (seis) espécies vegetais.

\subsection{Objetivos Específicos}

Determinar a densidade básica e as dimensões de fibras (comprimento, largura, diâmetro de lume e espessura da parede) das seis espécies mencionadas, bem como verificar suas correlações, por meio dos índices de Runkel, feltragem, Coeficiente de flexibilidade e Fração parede examinando os potenciais dessas matérias primas para produção de papel artesanal.

\section{REFERENCIAL TEORICO}

\subsection{Setor de celulose e papel}

Até a década de 50, praticamente toda a celulose era importada devido à isenção de impostos e a excelente qualidade do produto trazido do exterior, mas também pela falta de matéria prima adequada na época, ao elevado capital despendido para implantação da fábrica de celulose e à falta de capacitação técnica voltada à engenharia de processos, entre outros (ALMEIDA, 2013). Porém com o passar do tempo, o avanço de novas técnicas e tecnologias, o Brasil passou a apresentar, segundo Oliveira (2008), um grande potencial para a produção de florestas de rápido crescimento, base do setor de celulose e papel, devido ao clima, solo, à 
extensão do território, às técnicas silviculturais avançadas e à boa adaptação de espécies às características locais.

Dentre as espécies que melhor se adaptaram a essas condições o gênero Eucalyptus tem grande destaque, o que proporcionou ao Brasil um melhor desempenho na produção de pastas de madeira, em especial na produção de celulose de fibra curta de eucalipto, em que o país é o maior produtor mundial (MONTEBELLO; BACHA, 2013).

As exportações brasileiras deram um salto considerável a partir de 1978 como resultado das políticas de incentivo à indústria exportadora de celulose. Quanto ao destino das exportações brasileiras os maiores importadores são EUA, Alemanha, Japão, Itália, Reino Unido, França e Coreia do Sul, que são responsáveis pelas maiores importações de celulose do mundo (HILGEMBERG; BACHA, 2001).

Para Vidal e Hora (2012) as exportações globais vêm aumentando, passando de $21 \%$ em 2000 para 26\% em 2010. Apesar da tendência positiva, a fração da produção exportada de celulose ainda é inferior à de papéis. Segundo estimativas da RISI, o consumo aparente de papéis em 2011 teve um acréscimo de 1,7\% sobre o registrado em 2010. Para os próximos anos, é provável que a demanda por papéis continue sendo influenciada pelo crescimento do PIB e, uma vez que as perspectivas econômicas são favoráveis aos países emergentes, estes devem continuar praticando melhor desempenho do que os mercados maduros, à semelhança dos últimos anos.

O mercado mundial de papel está ligado principalmente à globalização em termos de hábitos de consumo, "desmaterialização" dos meios de informação, o aumento do poder aquisitivo de grandes massas de população residentes nos países em desenvolvimento, e a ascensão a uma nova classe média de hábitos mais sofisticados e demandantes (SILVA; BUENO; NEVES, 2015).

Atualmente, o setor de celulose e papel brasileiro ocupa o quarto lugar no ranking das nações produtoras de celulose de todos os tipos. Esse setor respondeu, em 2013, pela geração de cerca de 130 mil empregos diretos e pela arrecadação de tributos da ordem de $\mathrm{R} \$ 3,5$ bilhões (CGEE, 2016).

\subsection{Produção artesanal}

Desde os primórdios a produção de papel artesanal se fazia presente nas civilizações e, para Klock (2013), até o final do século XVIII a fabricação do papel era exclusivamente artesanal, porém com a revolução industrial os avanços na fabricação do papel fizeram com 
que a procura por novas matérias primas fibrosas se intensificasse, com o intuito de suprir as demandas.

Segundo Superbia \& Paula (2011) mais de 90\% das fibras de celulose utilizadas no Brasil para a fabricação de papel são derivadas da madeira. Este processo requer grandes quantidades de água, gerando com isso grande quantidade de efluentes, que causa grande incerteza do setor com relação às questões ambientais (KLOCK et al 2013).

Com crescente preocupação quanto ao meio ambiente que impulsionou o uso de recursos não agressivos ao planeta, o uso de fibras vegetais se torna uma boa alternativa por ser um material renovável, biodegradável e de baixo custo (CARDOSO, 2012), sendo que produção de papel artesanal economiza cerca de $60 \%$ da energia e $75 \%$ da água necessária para a produção de fibras virgens a partir da madeira (DANTAS, 2012).

Além das questões que envolvem a economia de energia e água, a fabricação de papel artesanal também se mostra alternativa a evitar o desperdício de resíduos agrícolas que seriam naturalmente descartados, uma vez que estes resíduos vegetais podem ter outros destinos como, por exemplo, matéria prima para a produção de papel artesanal.

Como a unidade básica formadora de papel é a celulose, e essa macromolécula pode ser encontrada na maioria das plantas, é possível afirmar, guardadas as devidas proporções, que qualquer vegetal pode ser usado para a fabricação de papel artesanal, uma vez que através do processo de polpação a celulose é separada da lignina.

A sazonalidade das produções de matérias prima não madeireiras torna-se um dos fatores limitantes para a produção com fibras alternativas, no entanto de acordo com Gatti (2007) citada por Bezerra (2017) existem diversas fontes de fibras vegetais alternativas para a fabricação de papel artesanal como: abacaxi, bambu, bananeira, cana-de-açúcar, coco, milho, agave, soja, além de aparas e papéis usados.

Desde 2003, a utilização da fibra reciclada é superior à da fibra virgem, diferença que aumenta desde então, tendo chegado à participação da fibra reciclada, no mix de produção mundial, a 56\% em 2010 (VIDAL; HORA, 2012).

Em alguns casos a eficiência do processo de produção artesanal pode ser tamanha que, segundo Coraiola \& Mariotto (2009), existe a possibilidade da realização de um "ciclo fechado" de produção, onde não são produzidos efluentes no processo. 


\subsection{Espécies do estudo}

\subsubsection{Agave americana $l$}

Pertencente à família das Agavaceae e nativa do México, está espécie foi introduzida primeiramente na Europa como planta ornamental e, com o passar do tempo, para finalidades têxteis. É formada por grandes rosáceas de folhas lanceoladas e muito espessas (xeromorfas), possui flores de cor amarelo pálido e é considerada como rizomatosa. Consiste em uma espécie muito resistente à seca e altas temperaturas (ELORZA et al., 2004). Suas folhas podem medir até 2,0 metros de comprimento e, em sua espessura possui fibras longitudinais muito resistentes e maleáveis, sendo que qualquer espécie desse gênero fornece fibras duras que são extraídas de suas folhas com a qual se fazem cordas, barbantes, tapetes. Além disso, pode ser utilizada no preparo da pasta celulósica para fabricar papel e na fabricação de cortisona (ORMOND, 2006).

\subsubsection{Musa spp.}

O gênero Musa pertencente às monocotiledôneas da família Musasceae são típicas de regiões úmidas podendo chegar até $9,0 \mathrm{~m}$, apresentam pseudocaule vegetativo e folhas embainadas (formando bainhas). O interesse pela bananeira como matéria prima para papel vem desde o século XVIII, devido ao seu pseudocaule constituído de $40 \%$ de fibras de celulose (SILVA, 1998)

Ainda segundo o autor Silva (1998), a produção de polpa celulósica a partir da bananeira seria limitada devido ao seu alto conteúdo hídrico, no entanto pode ser bastante utilizada artesanalmente uma vez que qualquer parte da planta pode ser usada na polpação como folhas, pedúnculo e rizoma, além de possuir uma baixa porcentagem de lignina.

\subsubsection{Saccharum spp.}

As espécies de cana-de-açúcar pertencem à família Poaceae e são provenientes da Ásia, apesar disso tiveram uma boa adaptação ao clima brasileiro apresentando um bom desenvolvimento sendo muito utilizada na produção alcooleira. (SANTOS, 2014)

Com o avanço nos estudos de aproveitamento de resíduos de produções, a cana-deaçúcar ganhou espaço no setor de celulose, uma vez que o bagaço constitui o maior resíduo lignocelulósico da agroindústria brasileira, sendo 40-50\% de celulose, 20-30\% de hemicelulose e 20-28\% de lignina (ANDRADE et al. 2014). 
Segundo Santos (2014), a cana de açúcar é um material fibroso não madeireiro do grupo das monocotiledôneas que, quando comparado com madeiras, proporciona facilidades no processo de produção de polpa celulósica

\subsubsection{Heliconia rostrata}

Nativas da América do Sul as heliconias são plantas tropicais com alto valor ornamental agregado e, atualmente, o gênero faz parte da família Heliconiaceae com um único representante. Podem ocorrer em variadas altitudes sendo mais raras em grandes altitudes e, mesmo sendo um gênero mais tropical existem cultivos protegidos em regiões da Itália, Alemanha e Holanda.

Apesar de existirem poucos estudos sobre as heliconias seus talos contem grande concentração de biomassa podendo ser utilizados na fabricação de papel artesanal (HOFMANN-GATTI, 2008).

\subsubsection{Arundo donax}

A cana do reino é uma espécie invasora no Brasil porem muito bem adaptada, acredita-se que tenha sua origem na Ásia e que pertencaça família das Poaceae (SIMÕES, 2013).

É uma espécie muito utilizada na construção de instrumentos de sopro e palhetas, usos medicinais, recuperação de áreas degradadas, além da produção de papel onde a Itália é um dos países pioneiros em seu uso. Pode chegar até 8,0 m tendo rizomas com características fibrosas.

\subsubsection{Ananas comosus,}

Caracteriza-se como uma infrutescência do grupo das monocotiledôneas pertencente à família Bromeliaceae, com origem no sul da América do Sul. O Brasil é um dos maiores produtores de abacaxi com mais de 63 mil hectares produtivos, porém ainda existem desperdícios associados à produção de partes tidas como resíduos mas que poderiam receber outras destinações, como é o caso da coroa do abacaxi utilizada para a produção papeleira (ROGÉRIO et al. 2007).

Um dos recursos alternativos para a produção de polpa celulósica para a fabricação de papel artesanal se encontra nas folhas do abacaxi. Quando exploradas corretamente, as folhas do abacaxi fornecem fibras longas utilizadas na fabricação de fios e tecidos além de polpa para a fabricação de papel (OLIVEIRA et al, 2004). 


\subsection{Caracterização Morfológica das Fibras}

Em relação ao potencial das fibras para a produção de papel bem como as dimensões das mesmas para a fabricação de um produto final de qualidade, e tomando como referência o gênero Eucalyptus como parâmetro de dimensões adequadas para a produção de papel, e o estudo de Gonçalez et al. (2014), espera-se que fibras vegetais de comprimentos, larguras e diâmetros de lume médios próximos a valores de $0,90 \mathrm{~mm} ; 16,91 \mu \mathrm{m} ; 5,59 \mu \mathrm{m}$ respectivamente apresentem um bom potencial para a produção de papel.

Em relação às fibras longas, tomando como referência o gênero Pinus excelente fornecedora de fibras longas na produção de papel (PEREIRA et al, 2002), espera-se que estas apresentem dimensões de comprimentos, larguras e diâmetros de lume médios próximos a valores de 3,5 mm; 46,7 $\mu \mathrm{m} ; 31,0 \mu \mathrm{m}$ respectivamente (KLOCK et al, 2005).

Contudo, as fibras não-madeireiras continuam com significação econômica em alguns países para a fabricação de papéis artesanais e especialidades comerciais. Essa classe de fibras oferece uma escala de comprimentos médios que vão de menos de $1 \mathrm{~mm}$ a mais de $120 \mathrm{~mm}$, enquanto a largura cobre toda a amplitude das fibras da madeira, de 10 a $50 \mu \mathrm{m}$. (PEPE, 2011).

Segundo estudos de Roja e Neves (2002) comparando trabalhos de Torres (1981), Semana et al. (1987), Alquini (1992), estudando variadas do gênero de Musa, foi observado que através das dimensões obtidas as fibras resultantes eram de um material desejável para a produção de papel sendo fibras flexíveis, com boa superfície de contato e boa união fibrafibra, o que permitiu classificá-las como fibras excelentes para fabricação de papel, apresentando valores médios de 3,91 mm de comprimento, 38,18 $\mu \mathrm{m}$ de largura e 30,55 $\mu \mathrm{m}$ de diâmetro de lume, o que caracteriza esta fibra como uma fibra longa (SOFFNER, 2001)

Já para o gênero Agave foram encontrados valores de médios de 2,6 $\mathrm{mm}$ de comprimento de fibra, $17,4 \mu \mathrm{m}$ de largura e $6,7 \mu \mathrm{m}$ de diâmetro de lume da fibra, mostrando que em relação à largura e ao diâmetro do lume as fibras apresentam dimensões semelhantes às de folhosas (AZZINI; CIARAMELLO; 1977).

No caso do abacaxi, as folhas em rosetas fornecem fibras brancas e flexíveis muito resistentes a tração e ao vapor, sendo consideradas boas propriedades para o papel artesanal. Com relação à Heliconia existem poucos estudos sobre o seu potencial, porem as fibras apresentam-se longas, o que confere alta resistência ao papel. Para a cana do reino destacamse principalmente seu colmo e folhas contendo $43 \%$ de celulose e baixo teor de lignina, sendo 
a baixa quantidade de lignina a característica mais requisitada pelo setor de celulose e papel (HOFMANN-GATTI, 2007)

Ainda segundo Hofmann-Gatti (2007) a fibra do bagaço da cana-de-açúcar é um material lenhoso muito importante para a produção de papel apresentando baixo teor de lignina e cerca de 44\% de celulose. Em estudos de Azzini et al. (1996), foram encontrados valores médios de 1,24 mm de comprimento, 4,15 $\mu \mathrm{m}$ de diâmetro de lume e 12,80 $\mu \mathrm{m}$ de largura da fibra, comparando com as fibras de Eucalyptus a fibra da cana-de-açúcar se apresenta mais estreita e mais longa, podendo ser utilizadas para a produção de celulose para usos que não requeiram altos níveis de resistência físico-mecânica.

\subsection{Correlações de fibras e índices associados}

O índice de Runkel é a relação entre a espessura da parede da fibra e o diâmetro do lume da mesma. Este índice indica o grau de flexibilidade da fibra gerando informações relativas à capacidade de união, resistência à tração e arrebentamento da fibra, além de estar relacionado com as propriedades mecânicas conferidas ao papel (FOELKEL; BARRICHELO, 1975).

Segundo Menegazzo (2012) esse índice confere um diagnóstico sobre o uso da fibra e pode variar de valores menores que 0,25 até valores maiores que 2,0, sendo que valores mais altos conferem qualidades piores das polpas para a fabricação de papel. Quando o índice de Runkel apresenta valores menores que 0,25 a fibra é classificada como excelente para papel. Quando esse valor se apresenta entre 0,25 e 0,5 a fibra é classificada como muito boa para fazer papel, e de 0,5 a 1,0 é classificada como boa para papel. Já para valores entre 1,0 e 2,0 essa classificação passa a ser regular para papel e valores maiores que 2,0 a fibra é classificada como ruim para papel.

Já a Fração da Parede expressa uma relação entre a espessura da parede e a largura da fibra e, está relacionado à rigidez da fibra influenciando diretamente nas propriedades mecânicas do papel (CORRÊA, 2016); (MIRANDA; CASTELO, 2012).

De acordo com Foelkel e Barrichelo (1975) esse índice proporciona uma correlação com a resistência ao rasgo, para valores acima de $40 \%$ a celulose produzida não é d boa qualidade uma vez que as fibras apresentam alta rigidez e pouca flexibilidade o que dificulta as interligações. Porém para valores abaixo dessa porcentagem limite espera-se uma alta resistência à tração e ao estouro, que por consequência geram maior resistência ao papel (SHIMOYAMA; WIECHETECK, 1993) citado por (CORRÊA, 2016). 
O Coeficiente de Flexibilidade expressa a relação entre o diâmetro do lume e a largura da fibra, tendo essa relação uma influência na resistência a tração e ao estouro, o que está relacionada ao grau de colapso das fibras durante o processo de fabricação do papel. (NISGOSKI et al, 2012). Para Foelkel e Barrichello (1975) citado por Miranda et al. (2012) e Nisgoski et al (2012) maiores valores do coeficiente de flexibilidade resultam em fibras mais flexíveis, maior resistência à ruptura e menor à tração, contribuindo para o aumento da resistência ao arrebentamento.

$\mathrm{O}$ índice de feltragem relaciona-se à flexibilidade da fibra analogamente ao coeficiente de flexibilidade, utilizando uma razão entre o comprimento e a largura da fibra. Este parâmetro possui correlação direta com a resistência ao rasgo, ao arrebentamento e entrelaçamento de fibras (NISGOSKI et al, 2012), sendo valores acima de 50 considerados como boas características do papel em relação aos parâmetros vinculados ao índice (DINWOODIE, 1965) citado por (NISGOSKI et al, 2012).

\section{METODOLOGIA}

\subsection{Material de estudo e Individualização das fibras}

A matéria prima das seis espécies (Agave americana l., Saccharum spp., Heliconia rostrata, Arundo donax, Musa spp. e roseta de Ananas comosus,) utilizadas neste estudo é proveniente da primeira etapa de análises que compõe o relatório técnico interno desenvolvido no LEME (Laboratório de Materiais Expressivos) e no LMC (Laboratório de Materiais Combustíveis) no primeiro semestre de 2017, sobre o estudo dos efluentes e das polpas celulósicas utilizadas na produção de papel artesanal.

Todas as espécies foram coletadas entre janeiro e fevereiro de 2017. A coleta de Agave americana l. (Pita) e Arundo donax (Cana do Reino) foi realizada nas proximidades do prédio da Maquete do campus Darcy Ribeiro da Universidade de Brasília, enquanto que a coleta de Saccharum spp. (Cana-de-açucar), se deu em uma pastelaria de Sobradinho (Distrito Federal DF) na forma de bagaço. O material da espécie Heliconia rostrata foi proveniente de uma chácara particular no DF. Já o material (rosetas) de Ananas comosus (Coroas de Abacaxi) adveio de lanchonetes e residências de Brasília. O material de Musa spp. é proveniente de uma doação feita por um produtor rural do DF.

A matéria prima coletada foi transformada em polpa para compor as análises do relatório interno do Laboratório de Materiais Expressivos, anteriormente citado, a partir daí a pesquisa foi desenvolvida por meio das analise das fibras das polpas produzidas. 
O estudo foi desenvolvido no Laboratório de Anatomia Vegetal do Instituto de Biologia e no Laboratório de Papel, ambos da Universidade de Brasília.

O material analisado em forma de polpa foi macerado e colocado em frascos identificados com o nome da espécie (Figura 1). A maceração foi feita cortando o material em pequenos pedaços e adicionando-os na solução de Franklin (mistura de ácido acético e peróxido de hidrogênio na proporção $1: 1)$ até a total cobertura do material macerado. $\mathrm{O}$ material preparado foi levado à estufa a $60{ }^{\circ} \mathrm{C}$ durante o tempo necessário para que fosse completamente dissociado, podendo variar de espécie para espécie em horas ou até dias.

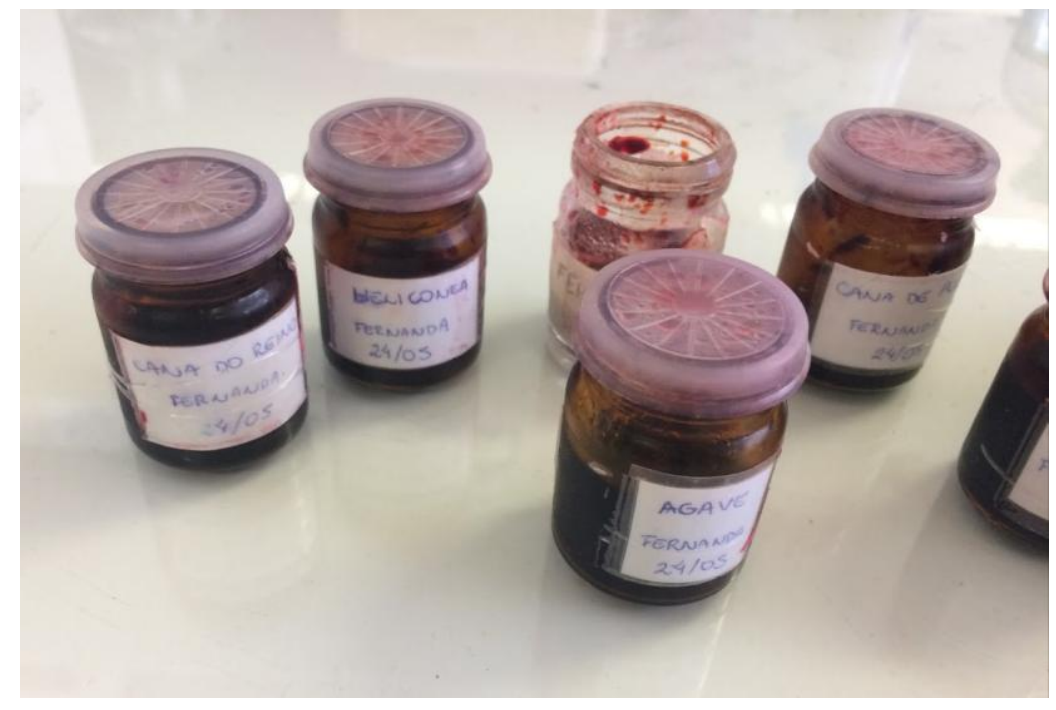

Figura 1 - Individualização das fibras das seis espécies em estudo coradas com safranina

Depois de retirado da estufa o material foi lavado cerca de 4 vezes com água destilada e uma vez com álcool $40 \%$ até que todo o cheiro do ácido de Franklin fosse removido, em seguida foi feita a coloração com safranina pura e posterior montagem das laminas. Foram feitas laminas temporárias onde se colocou cerca de três gotas de glicerina 1:1.

\subsection{Analise de Fibras}

Foram feitas dez lâminas para cada espécie e, em cada lâmina foram mensuradas dez dimensões de comprimento, largura e diâmetro do lúmen das fibras, totalizando 100 (cem) medições das dimensões avaliadas para cada espécie.

A medição das fibras foi feita com um microscópio ótico Olympus, com as objetivas de 4x e 40x, para medir o comprimento e a espessura, respectivamente. As fotos adquiridas das fibras no microscópio foram analisadas através do software Image-Pro Plus 6.0.

Com o auxílio do software foram obtidos os valores das dimensões a serem analisadas, bastando delinear o contorno das extremidades a serem mensuradas nas fibras (Figura 2). A 
espessura da parede das fibras foi obtida de forma indireta através da metade da subtração entre a largura da fibra e o diâmetro do lúmen, enquanto as demais dimensões mencionadas foram calculadas as seguintes relações:

- Índice de Feltragem (IF): Relação entre o comprimento médio e a largura média das fibras.

$$
I F=\frac{C}{D}
$$

- Coeficiente de flexibilidade (CF): Relação percentual entre a largura média do lúmen e a largura média das fibras.

$$
C F=\frac{L}{D} X 100
$$

- Fração Parede (FP): Relação percentual entre duas vezes a espessura média das paredes das fibras e a largura média da fibra.

$$
F P=\frac{2 E}{L} X 100
$$

- Índice de Runkel (IR): Relação entre duas vezes a espessura média das paredes das fibras e a largura média do lúmen.

$$
I R=\frac{2 E}{D}
$$

Onde:

$\mathrm{C}=$ comprimento da fibra;

$\mathrm{E}=$ espessura da parede;

$\mathrm{L}=$ largura da fibra;

$\mathrm{D}=$ diâmetro do lume. 


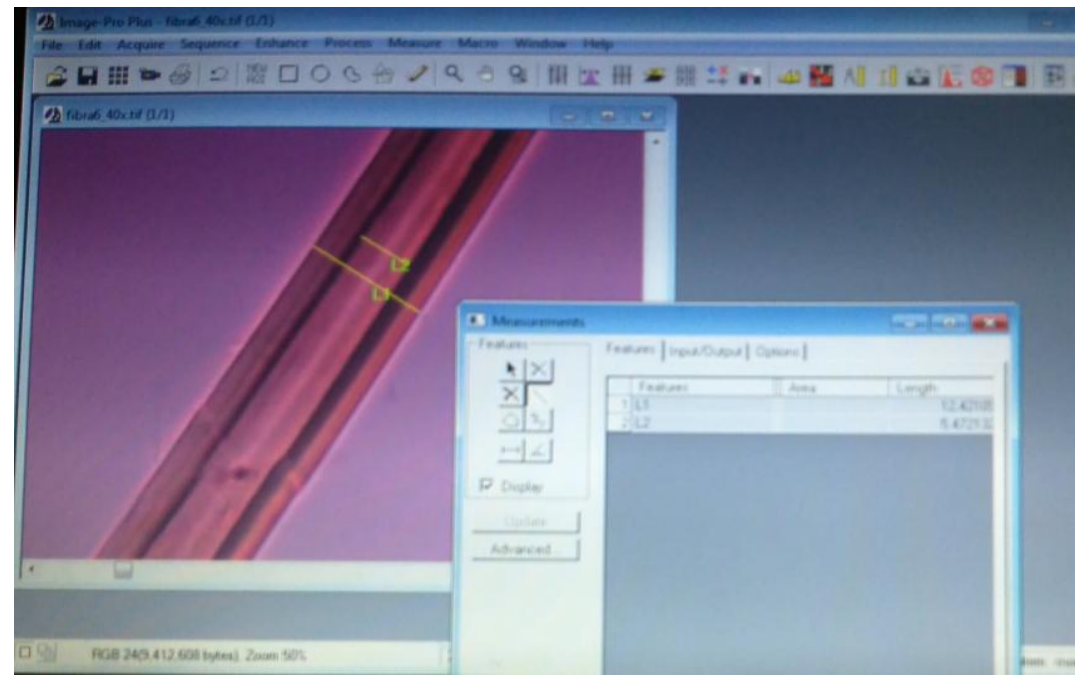

Figura 2 - Mensuração das dimensões de comprimento, largura e diâmetro do lúmen através do software Image Pro Plus 6.0

\subsection{Determinação da densidade básica}

A densidade básica foi determinada utilizando-se o Método do Máximo Teor de Umidade proposto por Foelkel et al. (1971):

$$
D b=\frac{1}{\frac{P U A}{P S A}-0,346}
$$

Onde:

$\mathrm{Db}=$ Densidade básica $\left(\mathrm{g} / \mathrm{cm}^{3}\right)$.

PSA $=$ peso seco da amostra.

PUA = peso úmido da amostra.

Para a obtenção dos parâmetros necessários para a densidade básica a partir do método do Máximo Teor de Umidade foram padronizadas sete amostras de aproximadamente $20 \mathrm{~g}$ para cada uma das espécies estudadas, totalizando 42 amostras. Estas foram identificadas (Figura 3) e submersas em água em um recipiente plástico por mais de 15 dias, até a sua saturação (Figura 4). 


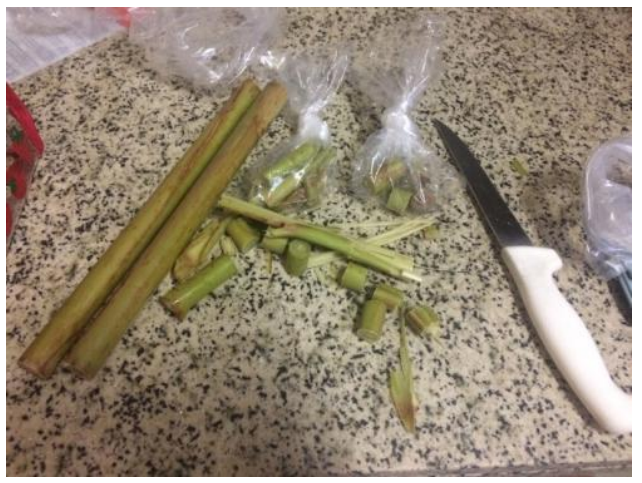

Figura 3 - Preparação e padronização das amostras para submersão em água.

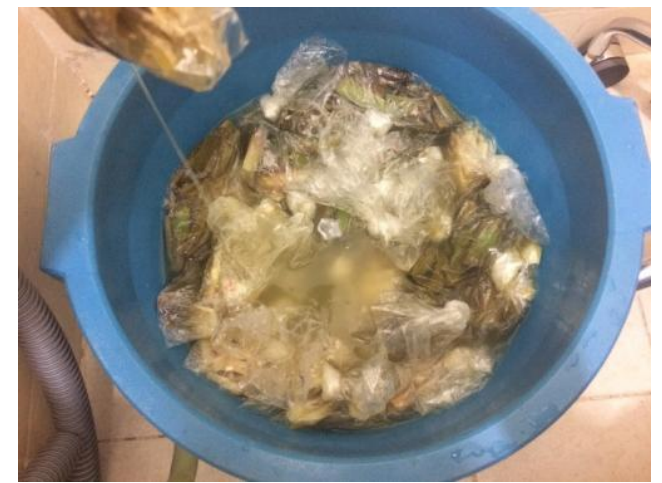

Figura 4 - Amostras das espécies seis espécies estudadas submersas em água

Para se medir o peso seco das amostras, as mesmas foram secas em estufa com temperatura de $70^{\circ} \mathrm{C}$ (Figura 5), até o alcance do peso constante.

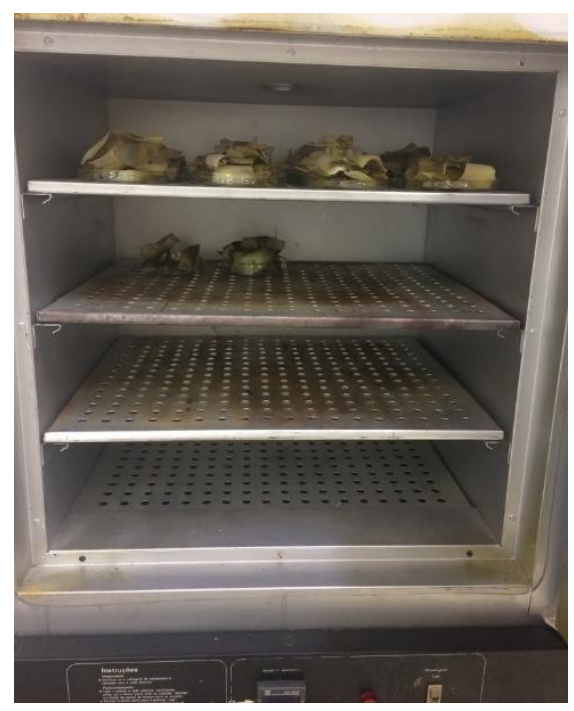

Figura 5 - Amostras sendo retiradas da estufa depois de completamente secas para posterior pesagem.

Foi necessário pesar a matéria saturada (Figura 6) e depois pesá-la seca, assim com ambos os dados e a fórmula de densidade básica, pode-se obter a densidade do material. 


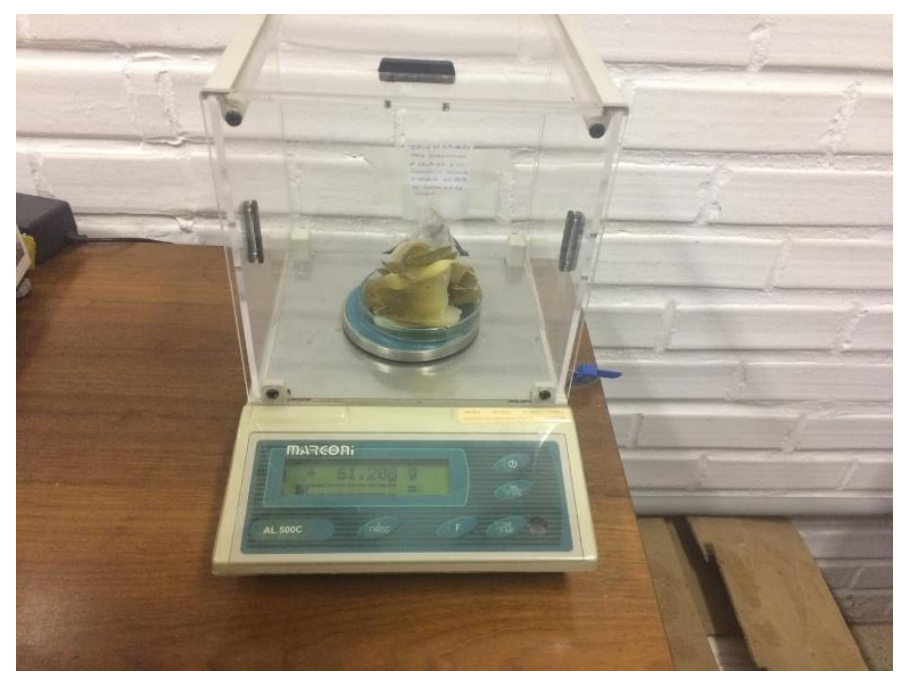

Figura 6 - Amostras úmidas pesadas em balança de precisão.

Os dados obtidos de fibras e densidade foram analisados utilizando estatística descritiva e em comparação com a literatura.

\section{RESULTADOS E DISCUSSÃO}

A partir dos dados obtidos pelas medições das fibras e do material fibroso das espécies em estudo foram obtidos o comprimento, a largura e a espessura da parede, assim como os índices de enfeltramento, coeficiente de flexibilidade, fração parede, índice de Runkel, além da densidade básica.

Segundo Gonçalez et al. (2014), as dimensões das fibras são indicadores importantes do potencial de uma madeira para a fabricação de celulose e papel. Estas exercem influência direta nas variáveis do processo, principalmente no grau de refino, na qualidade da pasta e, consequentemente, nas resistências físicas e mecânicas do papel.

A Tabela 1 apresenta os valores obtidos nas determinações das dimensões das fibras. Dentre as espécies estudadas a Musa spp. (bananeira) apresentou maior comprimento médio de fibra $(2,79 \mathrm{~mm})$, aproximando-se ao comprimento médio das fibras de coníferas, que pode variar de 3,5 a 4,0 mm, conferindo maior resistência à celulose quando comparada com as de fibras curtas (MENEGAZZO, 2012). 
Tabela 1 -Valores das dimensões das fibras das seis espécies estudadas.

\begin{tabular}{|c|c|c|c|c|c|}
\hline Espécie & Valor & $\begin{array}{c}\text { Comprimento } \\
\text { (mm) }\end{array}$ & $\begin{array}{c}\text { Largura } \\
\qquad(\mu \mathrm{m})\end{array}$ & $\begin{array}{c}\text { Diâmetro do } \\
\text { Lúmen } \\
(\mu \mathrm{m})\end{array}$ & $\begin{array}{l}\text { Espessura da } \\
\text { parede celular } \\
\qquad(\mu \mathrm{m})\end{array}$ \\
\hline \multirow{4}{*}{ americana $l$} & Máximo & 3,88 & 21,71 & 8,07 & 7,92 \\
\hline & Mínimo & 1,40 & 5,71 & 0,62 & 2,49 \\
\hline & Médio & 2,19 & 11,69 & 2,84 & 4,42 \\
\hline & Desvio Padrão & 0,49 & 2,92 & 1,48 & 1,13 \\
\hline \multirow{4}{*}{ Arundo donax } & Máximo & 1,86 & 15,15 & 7,90 & 4,62 \\
\hline & Mínimo & 0,38 & 3,87 & 0,62 & 1,35 \\
\hline & Médio & 0,84 & 7,74 & 2,23 & 2,75 \\
\hline & Desvio Padrão & 0,29 & 2,03 & 1,36 & 0,62 \\
\hline \multirow{4}{*}{ Musa spp } & Máximo & 4,80 & 26,89 & 18,44 & 7,39 \\
\hline & Mínimo & 1,44 & 5,18 & 1,51 & 1,47 \\
\hline & Médio & 2,79 & 14,34 & 6,44 & 3,94 \\
\hline & Desvio Padrão & 0,69 & 4,61 & 3,43 & 1,06 \\
\hline \multirow{4}{*}{$\begin{array}{c}\text { Heliconia } \\
\text { rostrata }\end{array}$} & Máximo & 3,66 & 19,53 & 10,29 & 5,81 \\
\hline & Mínimo & 1,23 & 5,43 & 0,58 & 1,66 \\
\hline & Médio & 2,41 & 9,97 & 2,88 & 3,54 \\
\hline & Desvio Padrão & 0,56 & 2,73 & 1,75 & 0,93 \\
\hline \multirow{4}{*}{$\begin{array}{l}\text { Roseta de } \\
\text { Ananas } \\
\text { comosus }\end{array}$} & Máximo & 3,67 & 10,62 & 3,95 & 4,21 \\
\hline & Mínimo & 0,82 & 2,44 & 0,32 & 0,75 \\
\hline & Médio & 1,74 & 4,34 & 1,33 & 1,50 \\
\hline & Desvio Padrão & 0,56 & 1,40 & 0,72 & 0,49 \\
\hline \multirow{4}{*}{ Saccharum spp } & Máximo & 2,12 & 22,82 & 13,80 & 7,00 \\
\hline & Mínimo & 0,66 & 6,82 & 1,09 & 2,30 \\
\hline & Médio & 1,23 & 13,37 & 4,54 & 4,41 \\
\hline & Desvio Padrão & 0,33 & 3,47 & 2,89 & 1,02 \\
\hline
\end{tabular}

Segundo o SENAI (2013) a classificação de coníferas e folhosas, quanto ao comprimento de fibras, situa-se nas faixas entre 3 a $5 \mathrm{~mm}$ e 0,5 a $1,5 \mathrm{~mm}$, respectivamente. As espécies estudadas, quanto a este parâmetro, situam-se entre as coníferas e folhosas, pois possuem comprimento médio de fibras entre $1,5 \mathrm{~mm}$ e $3,0 \mathrm{~mm}$, exceto para as espécies Arundo donax e Saccharum spp. Estas duas espécies possuem características de comprimento de fibra curta. A polpa de celulose composta de fibras mais longas tem aplicação nos papéis que precisam de uma maior resistência, como é o caso do papel usado na fabricação de embalagens e também no papel cartão. As espécies Musa sp, Heliconia rostrata e Agave americana l, parecem ter esta potencialidade. 
Em relação à resistência ao colapso das fibras, essa característica pode ser relacionada à espessura da parede das mesmas, ou seja, fibras com parede celular mais espessas tendem a ser menos susceptíveis ao colapso (CAMARGO et al, 2015). A maior espessura das paredes foi observada nas espécies de Agave americana l e Saccharum spp.

A densidade básica é um dos parâmetros mais utilizados para determinar a qualidade da matéria-prima para a produção de celulose, devido a sua relação com tempo de cozimento, separação das fibras e concentração de $\mathrm{NaOH}$, podendo causar interferências além de estar diretamente ligada com a qualidade do produto final (BEZERRA, 2017).

Foelkel (2009) citado por Camargo et al. (2015), complementa que uma maior densidade básica dificulta a deslignificação e impregnação, gerando polpas com menores rendimentos e maiores teores de rejeitos.

Apesar de haver uma estreita relação entre a espessura da parede e a densidade da espécie, a Arundo donax apresentou maior densidade básica (Tabela 2), o que pode ser explicado pela influência do diâmetro do lúmen e da largura da fibra, uma vez que, apesar de paredes menos espessas quando compara com as espécies Agave americana l e Saccharum spp, a Arundo donax apresenta uma menor largura quando comparada com as mesmas, explicando sua maior densidade básica.

Tabela 2 - Densidade básica média das seis espécies em estudo pelo método do máximo teor de umidade.

\begin{tabular}{|c|c|c|c|c|}
\hline Espécies & $\begin{array}{c}\text { Máximo } \\
\left(\mathbf{g} / \mathbf{m}^{3}\right)\end{array}$ & $\begin{array}{c}\text { Mínimo } \\
\left(\mathrm{g} / \mathrm{m}^{3}\right)\end{array}$ & $\begin{array}{c}\text { Densidade Básica } \\
\text { Média } \\
\left(\mathrm{g} / \mathbf{m}^{3}\right)\end{array}$ & Desvio Padrão \\
\hline Agave americana $l$. & 0,178 & 0,081 & 0,122 & 0,037 \\
\hline Arundo donax & 0,147 & 0,109 & 0,226 & 0,006 \\
\hline Heliconia rostrata & 0,104 & 0,087 & 0,094 & 0,005 \\
\hline Musa spp & 0,272 & 0,022 & 0,064 & 0,091 \\
\hline $\begin{array}{l}\text { Roseta de Ananas } \\
\text { comosus }\end{array}$ & 0,112 & 0,071 & $\mathbf{0 , 0 8 9}$ & 0,013 \\
\hline Saccharum spp. & 0,147 & 0,109 & 0,126 & 0,014 \\
\hline
\end{tabular}

A Tabela 3 apresenta a síntese dos índices para realizar a caracterização morfológica das seis espécies em estudo, baseado nas dimensões médias relativas às fibras. 
Tabela 3 - Dimensões médias e índices calculados comparando as seis espécies estudadas.

\begin{tabular}{lcccccccc}
\hline Espécies & $\begin{array}{c}\mathbf{C} \\
(\mathbf{m m})\end{array}$ & $\mathbf{L}(\boldsymbol{\mu m})$ & $\mathbf{D}(\boldsymbol{\mu m})$ & $\mathbf{E}(\boldsymbol{\mu m})$ & $\mathbf{I F}$ & $\mathbf{C F}(\boldsymbol{\%})$ & $\begin{array}{c}\mathbf{F P} \\
(\boldsymbol{\%})\end{array}$ & $\mathbf{I R}$ \\
\hline Agave americana l. & 2,19 & 11,69 & 2,84 & 4,42 & 187,89 & 24,31 & 75,68 & 3,11 \\
Arundo donax & 0,84 & 7,74 & 2,23 & 2,75 & 109,48 & 28,83 & 71,17 & 2,46 \\
Heliconia rostrata & 2,41 & 9,97 & 2,88 & 3,54 & 241,65 & 28,91 & 71,08 & 2,45 \\
Musa spp & 2,79 & 14,34 & 6,44 & 3,94 & 194,98 & 44,93 & 55,06 & 1,22 \\
Roseta de Ananas comosus & 1,74 & 4,34 & 1,33 & 1,50 & 401,68 & 30,60 & 69,39 & 2,26 \\
Saccharum spp. & 1,23 & 3,37 & 4,54 & 4,41 & 92,14 & 33,98 & 66,01 & 1,94 \\
\hline
\end{tabular}

C: comprimento de fibra, L: largura da fibra, D: diâmetro do lúmen, E:espessura da parede; IF: índice de enfeltramento, CF: coeficiente de flexibilidade, FP: fração parede e IR: índice de Runkel

Em um estudo comparativo de Azzini e Ciaramello (1977) o gênero Agave apresentou baixos coeficientes de flexibilidade, o que pode estar relacionado com o baixo valor obtido para o mesmo parâmetro na espécie Agave americana l. Isso implica um produto final com menor resistência à tração e ao arrebentamento, além de pouca superfície de contato das fibras dificultando a união fibra a fibra.

Quanto ao índice de Runkel, relativo às propriedades mecânicas conferidas ao papel, a espécie Agave americana l. foi identificada como a menos indicada para a fabricação de papel, uma vez que apresentou valores superiores a 2,0 indicando uma maior rigidez e dificuldade de união e menores ligações entre si (MENEGAZZO, 2012). Além disso, o resultado obtido no índice de fração parede ratifica tal característica, uma vez que o mesmo apresentou valores maiores que 60\% (FOELKEL, 1978).

Comparando os parâmetros analisados das fibras de Agave americana l., Heliconia rostrata, Musa spp. e roseta de Ananas comosus que apresentaram maiores comprimentos de fibras, com os mesmos parâmetros morfológicos obtidos para Pinus elliottii no estudo de Foelkel et al. (1976), os índices de enfeltramento se apresentaram bem superiores aos esperados para os de fibras longas.

Estudos de Rocha e Potiguar (2007) e Pereira (2001) mostram maiores índices de enfeltramento em espécies não madeireiras, conferindo uma alta resistência ao rasgo (FILHO et al, 1984), o que explicaria os altos valores obtidos para este índice nas espécies em questão.

Tanto a espécie Arundo donax como a Heliconia rostrata e a roseta de Ananas comosus estão classificadas no grupo $\mathrm{V}$ do índice de Runkel, o que indica um comprometimento na qualidade das fibras celulósicas para a produção de papel, sendo que as três espécies também apresentam coeficiente de flexibilidade abaixo de $30 \%$, influenciando 
negativamente no colapso das fibras e, por sua vez, na superfície de contato das mesmas e união fibra a fibra (PEREIRA, 2001)

Já as espécies de Saccharum spp. (cana-de-açucar) e Musa spp. (bananeira), seguindo o mesmo autor, foram classificadas na categoria IV do índice de Runkel, apresentando um potencial regular das fibras para a produção de papel, coeficiente de flexibilidade com pouco grau de colapso e superfície de contato, resultando em pouca capacidade de união fibra a fibra. Porém segundo Silva (1998), o potencial da bananeira seria limitado devido ao seu alto teor hídrico, porém o que se observa é que a espécie é apresenta um desempenho satisfatório no processo de polpação devido a sua baixa porcentagem de lignina e da variedade das partes da planta que podem ser usadas no processo.

Em relação ao índice fração parede, apenas a espécie Musa spp. apresentou valores abaixo de $60 \%$, o que indica uma maior facilidade de interligação de fibras influindo positivamente na formação da folha de papel (BOSCHETTI et al., 2015).

Comparando as espécies de Arundo donax (cana do reino) e Saccharum spp com estudos relativos a parâmetros morfológicos para espécies de fibras curtas, uma vez que as mesmas apresentaram seus comprimentos com esta característica apesentaram um coeficiente de flexibilidade superior ao obtido por Ferreira et al. (1996) para E. globulus e de Santos (2005) para híbridos de E. grandis x E. urophylla.

Assim como o coeficiente de flexibilidade, o índice de enfeltramentamento também apresentou maiores valores para as espécies de Arundo donax e Saccharum spp quando comparado em estudos feitos com eucalipto por Santos (2005). Os índices de Runkel e fração parede, ainda para as duas espécies, também apresentaram valores superiores, sendo estes quase o dobro do observado para híbridos de E. grandis x E. urophylla (MENEGAZZO 2012).

Estes altos índices observados podem ser correlacionados com o uso de espécies não madeireiras, uma vez que estas apresentam índices superiores aos esperados para espécies madeireiras de fibras curtas, como observado por Pereira et al (2004), assim como observado em estudos de Azzini et al. (1977) para o gênero de Guadua que também apresenta comprimentos de fibras próximos aos classificados como curtas e parâmetros morfológicos com valores semelhantes aos obtidos no estudo para as duas espécies.

Por outro lado, deve-se considerar que a comparação entre estudos de espécies madeireiras e não madeireiras pode levar a interpretações nem sempre corretas, pois trata-se de materiais com característica diferentes. Além disso, as metodologias utilizadas no estudo 
foi para o material madeira, o que também pode ter influenciado nos parâmetros determinados.

A fabricação de celulose e papel irá confirmar as características dos materiais estudados determinando praticamente seu potencial de utilização, sendo que segundo estudos de Souza et al. (2015), a produção de celulose no Brasil veem ganhando espaço com 165 mil toneladas de celulose de fibras alternativas produzidas no ano de 2013.

\section{CONCLUSÕES}

Após todas as análises, verificou-se que a espécie Saccharum spp. apresentou morfologia para a produção de celulose que proporcionam melhores caraterísticas ao produto final entre as espécies classificadas como de fibras curtas, apresentando melhores índices de fração parede, índice de Runkel e coeficiente de flexibilidade. Apesar de a espécie não ter apresentando um índice de enfeltramento tão bom quanto o da espécie Arundo donax, também classificada como fibra curta, a Saccharum spp obteve melhor desempenho nos outros três índices analisados além de ter menor densidade básica, o que propicia uma melhor deslignificação durante o processo de polpação.

Já para a categoria que se aproximam de fibras longas, foram observadas quatro espécies, Agave americana l., Heliconia rostrata, Musa spp. e roseta de Ananas comosus. Duas espécies se destacaram apresentando melhores desempenhos, sendo o critério de índice de Runkel e fração parede determinantes para a escolha da fibra com propriedades para gerar um produto final de melhores características. Com base nisso, as fibras que apresentaram melhores índices dentro das espécies consideradas de fibras longas foram as de Musa spp., sendo a roseta de Ananas comosus a segunda melhor dentro da mesma categoria.

Analisando as seis espécies em conjunto, a espécie de Musa spp. apresentou características morfológicas que conferem melhores características ao papel produzido, além de possuir bons índice de enfeltramento, Runkel, coeficiente de flexibilidade e fração parede, sua densidade foi de $0,06 \mathrm{~g} / \mathrm{cm}^{3}$, sendo que altas densidades básicas afetam na produção de polpa celulósica.

Para confirmar o potencial positivo ou negativo das espécies estudadas, sugere-se a produção de papel com as mesmas e análises de seus testes e propriedades. Além disso, o que se observa é a não existência de um padrão de referência para comparação e análise do potencial de fibras alternativas para a produção de papel artesanal. 


\section{REFERÊNCIAS}

ALMEIDA, V. B De. Caracterização, Análise e Perspectivas da Matriz Energética do Setor de Papel e Celulose. 2013. 66 p. Dissertação (Mestrado em Agroenergia) - Escola de Economia de São Paulo da Fundação Getúlio Vargas, São Paulo, 2013.

ANDRADE, J. C. F.; SANTOS, L.S.; SILVA, V. L.; OLIVEIRA, K. G.; CAMPOS, L. M. A.; SILVA, E. G.; COSTA, G. I. Q. Obtenção da celulose oriunda do bagaço da cana de açúcar (Saccharum officinarum) e caracterização por FTIR/DRX. In: 54 Congresso Brasileiro de Química. Natal, 2014.

AZZINI, A.; CIARAMELLO, D.; NAGAI, V. Densidade básica e dimensão das fibras em bambus do gênero Guadua. Bragantia, Campinas, v. 36, 1977 (Nota $1^{\circ}$ )

AZZINI, A.; CIARAMELlO, D. Dimensões das fibras em Agave. Bragantia, Campinas, XXXV-XXXVIII, v. 36, 1977. (Nota $9^{\circ}$ )

AZZINI, A.; ZIMBACK, L.; TOMAZ, R. M. A. G. Palha de cana de açúcar como matériaprima na obtenção de fibras celulósicas para papel. Bragantia, Campinas, v. 55, n.1, p.137140, 1996. (Nota)

BEZERRA, W. C. S. Caracterização tecnológica das fibras de hibiscus rosa-sinensis e sua utilização para fabricação de papel artesanal. 2017. 28 p. Trabalho de Conclusão de Curso (Bacharelado em Engenharia Florestal) - Universidade de Brasília, Brasília, 2017.

BOSCHETTI, W. T. N.; PAES, J. B.; OLIVEIRA, J. T. S.; DUDECKI, L. Características anatômicas para a produção de celulose do lenho de reação das arvores inclinadas de eucalipto. Pesquisa Agropecuária Brasileira. Brasília, v. 50, n.6, p. 459-467, 2015.

CAMARGO, S. Q. C. A.; SILVA, T. J.; COSTA, D. M. Influência da dimensão e qualidade dos cavacos na polpação. Revista Eletrônica em Gestão, Educação e Tecnologia Ambiental Santa Maria, v. 19, n. 3, p. 813-820, 2015. 
CARDOSO, M. S. Aproveitamento da casca do coco verde (Cocos nucifera L.) para produção de polpa celulósica. 2012. Trabalho de Conclusão de Curso (Bacharelado em Engenharia Florestal) - Universidade de Brasília. Brasília, 2012.

Centro de Gestão e Estudos Estratégicos - CGEE. Centro Tecnológico em Celulose e Papel Proposta de criação - Brasília, 2016.

CORAIOLA, M.; MARIOTTO S. C. Proposta metodológica para produção artesanal de papel utilizando a fibra de pseudocaule da bananeira. Revista Acadêmica de Ciências Agrárias e Ambientais, Curitiba, v. 7, n. 2, p. 207-216, 2009.

CORRÊA, R. Caracterização química e morfológica da madeira de Cupressus lusitânica Mill. para a produção de polpa celulósica. Dissertação (Bacharel em Engenharia Florestal) Universidade Federal de Santa Catarina, Curitibanos, 2016.

DANTAS, M R. Prospecção Das Tecnologias Para Produção De Fibra Secundária Branqueada De Celulose Por Processamento De Papel Recuperado De Pós-Consumo. 2012. 142p. Dissertação (Mestrado em Engenharia de Processos Químicos e Bioquímicos) - Centro Universitário do Instituto Mauá de Tecnologia. São Caetano do Sul, 2012.

DINWOODIE, J. M. The relationship between fiber morphology and paper properties: a review of literature. Tappi Journal, v.48, n.8, p.440- 447, 1965

ELORZA, M. S.; VESPERINAS, E. S.; SÁNCHEZ, E. D. Agave americana l. Atlas de las plantas alóctonas invasoras en España. 2004.

E SILVA, C. A. F.; BUENO, J. M.; NEVES, M. R. A Indústria De Celulose E Papel No Brasil. Guia ABTCP De Fornecedores E Fabricantes - Celulose E Papel 2015/2016. 112p.

FERREIRA， P. J.; CARVALHO, M. G.; MARTINS, A. A.; FIGUEIREDO, M. M. Caracterização dimensional de fibras de eucalipto. XV Congresso Nacional da Tecnicelpa, 208-219, Aveiro, Portugal. 1996. 
FOELKEL, C. E. B. Elementos de vaso e celuloses de eucalipto. Grau Celsius, 2009. Disponível em: <http://www.eucalyptus.com.br/eucaliptos /PT04_vasos.pdf>. Acesso em: 22 nov. 2017.

FOELKEL, C.E.B.; BRASIL, M.A.M.; BARRICHELO, L.E.G. Métodos para determinação da densidade básica de cavacos para coníferas e folhosas. IPEF, Piracicaba, v. 2, n. 3, p. 6574, 1971.

FOELKEL, C. E. B; BARRICHELO, L. E. G. Tecnologia de celulose e papel. Piracicaba: ESALQ 207p. 1975. (Apostila)

FOELKEL, C. E.; BARRICHELO, L. E. G. Utilização de madeiras de essências florestais nativas na obtenção de celulose: bracatinga (Mimosa bracatinga), embaúba (Cecropia sp.), caixeta (Tabebuia cassinoides) e boleira (Joannesia princeps). IPEF, n.10, p. 43-56, 1975.

FOELKEL, C.E.B.; BARRICHELO, L.E.G. Relações entre características da madeira e propriedades da celulose e papel. O Papel, São Paulo, v.36, n.9, p.49- 53, 1975.

GONÇALEZ, J. C.; SANTOS, G. L Dos.; JUNIOR, F. G. S Da.; MARTINS, I. S.; COSTA, J De. A. Relações entre as dimensões de fibras de densidade da madeira ao longo do tronco de Eucalyptus urograndis. Scientia Forestalis, Piracicaba, v. 42, n. 101, p. 81-89, mar. 2014.

HILGEMBERG, E.; BACHA, C. J. A evolução da indústria brasileira de celulose e sua atuação no mercado mundial. Artigo para BNDES (Banco Nacional de Desenvolvimento Econômico e Social) - Revista Análise Econômica, v. 19, n.36. 164 p, 2001.

HOFMANN-GATTI, T.; SUAREZ, P. A. Z.; TEIXEIRA, M. B. D.; BEZERRA, W. C. S. Estudo dos efluentes e das polpas celulósicas utilizadas na produção de papel artesanal. Relatório Técnico, LEME/VIS/IdA/UnB, LMC/IQ, 2017.

HOFMANN-GATTI, T. Do berço ao berço: agregação de valor e desemprenho socioambiental para a produção de papeis especiais com resíduos da agricultura. Dissertação (Doutorado em Desenvolvimento Sustentável) - Universidade de Brasília, 2008 
HOFMANN-GATTI, Thérèse. A história do papel artesanal no Brasil. São Paulo: ABTCP, 2007.

KLOCK, U; ANDRADE, A. S. De; HERnANDEZ, J. A. Polpa e papel. Manual didático de polpa e papel $3^{\text {a }}$ edição. Curitiba, 2013.

KLOCK, U.; MUÑIZ, G. I. B.; HERNANDEZ, J. A; ANDRADE, A S. Química da madeira. $3^{\text {a }}$ edição. Universidade Federal do Paraná. Curitiba, 2005.

MACEDO, A. R. P.; VALENÇA, A. C. V. A Indústria De Papel No Brasil E No Mundo: Uma visão geral. Gerencia Setorial de Papel e Celulose do BNDS. BNDS Setorial, 1996.

MENEGAZZO, M. L. Características morfológicas de celuloses branqueadas de Pinus e Eucalyptus em analisador óptico automático de fibras. Dissertação (Mestrado em Ciências Florestais) - Universidade Estadual Paulista “Júlio Mesquita Filho”. Botucatu, 2012.

MIRANDA, R. E. S. Impactos Ambientais Decorrentes De Resíduos Gerados Na Produção De Papel E Celulose. Dissertação (Graduação em Engenharia Florestal) - Universidade Federal Rural do Rio de Janeiro. Seropédica, 2008.

MIRANDA, M, C De.; CASTELO, P. A. R. Avaliações anatômicas das fibras de madeira de Parkia gigantocarpa ducke. Ciência da Madeira (Braz. J. Wood Sci.), Pelotas, v. 3, n. 2, nov. 2012.

MONTEBELLO, A. E. S.; BACHA, C. J.C. Impactos da restauração do setor de celulose e papel no Brasil sobre o desempenho de suas indústrias. Estudos Econômicos, São Paulo, v.43, n.1, p.109-137. 2013

NAVARRO, R. M. S.; NAVARRO, F. M. S.; TAMBOURGI, E. B. Estudos de Diferentes Processos da Pasta Celulósica para a Fabricação de Papel. Revista Ciência \& Tecnologia, v.1, n.1, p. 1-5, 2007.

NISGOSKI, S; MUÑIZ, G. I. B. De; TRIANOSKI, R; MATOS, J. L. M. De; VENSON, I. Características anatômicas da madeira e índices de resistência do papel de Schizolobium 
parahyba (Vell.) Blake proveniente de plantio experimental. Scientia Forestalis, Piracicaba, v. 40, n. 94, p. 203-211, jun. 2012

OLIVEIRA, E. L.; LADCHUMANANANDASIAM, R.; ALEXANDRE, M. E. O.; VERÍSSIMO, S. A.; BEZERRA, C. M.; SOUZA, E. C. Produção e caracterização das fibras da folha do abacaxi. XV Congresso Brasileiro de Engenharia Química/COBEQ. Curitiba, 2004

OLIVEIRA, L. J. R. Amostragem não destrutiva e qualidade da madeira em clones de Eucalyptus spp. 2008. 62f. Dissertação (Pós-Graduação em Ciência e Tecnologia da Madeira) - Universidade Federal de Lavras, Lavras, MG.

ORMOND, J. G. P. Glossário de termos usados em atividades agropecuárias, florestais e ciências ambientais. 3ª Edição. Banco Nacional de Desenvolvimento Econômico e Social. 2006.

OSORIO, E. G. Industria de Papel e Celulose: Estudo de Caso da Implantação da VPC Florestal no Extremo Sul do Rio Grande do Sul. Dissertação (Graduação em Ciências Econômicas) - Universidade de Sana Catarina, Florianópolis, 2007.

PEPE, L. Fontes de fibras para papel. O Nosso Papel - ABTCP, ano 7, edição ${ }^{\circ}$ 25, 2011.

PEREIRA, S. J. Avaliação das características e propriedades da polpa celulósica de Mauritia vinifera Martius e Bactrís inundata Martius (palmae) pelo processo kraft. Dissertação (Doutorado em Ciências Florestais) - Universidade Federal do Paraná, Curitiba, 2001.

PEREIRA, S. J.; MUNIZ, G. I. B.; KAMANINSKI, M.; KLOCK, U., NISGOSKI, S., FABROWSKI, F. J. Celulose de tucum (Bactris inundata Matius). Scientia florestalis. São Paulo, n. 65 p. $130-140,2004$

FILHO, A. M.; GOMIDE, J. L.; CONDÉ, A. R. Viabilidade da constituição química e das características dimensionais das fibras do Bambusa vulgaris. Revista árvore. Viçosa, Minas Gerais, v. 8, n.1, p. 12-27, 1984. 
RESENDE, F. S. Da. Caracterização do Processo de Produção de Pasta de Celulose do Sulfito. Dissertação (Mestrado em Engenharia do Ambiente) - Universidade de Aveiro. Portugal, 2012.

ROGERIO, M. C. P.; BORGES, I.; NEIVA, J. N. M.; RODIGUEZ N. M.; PIMENTEL, J.C.M.; MARTINS, G. A.; RIBEIRO, T. P.; COSTA, J. B.; SANTOS, S. F.; CARVALHO, F. C. Valor nutritivo do resíduo da indústria processadora de abacaxi (Ananas comosus l.) em dietaspara ovinos. 1. Consumo, digestibilidade aparente e balanços energético e nitrogenado. Arquivo Brasileiro de Medicina Veterinária e Zootecnia, v.59, n.3, p.773-781, 2007.

SANTOS, C. P.; REIS, I. N. Dos; MOREIRA, J. E. B.; BRASILEIRO, L. B. Papel: Como Se Fabrica. Revista Química Nova Na Escola - seção Química e Sociedade, n. 14, nov. 2001.

SHIMOYAMA, V. R. S.; WIECHETECK, M. S. S. Características da madeira e da pasta termomecânica de Pinus patula var. tecunumanii para produção de papel imprensa. IPEF, Piracicaba, v. 9, n. 27, p.63-80, ago. 1993.

SENAI, Serviços Nacional de Aprendizagem. Celulose. SENAI-SP. São Paulo. 2013. 352p.

SIMÕES, K. C. Distribuição de cana do reino (Arundo donax l.) no Distrito Federal. 2013. Dissertação (Mestrado em Ecologia) - Universidade de Brasília. Brasília.

SILVA, A. G. Utilização do pseudocaule da bananeira para produção de celulose e papel. 1998. Dissertação (Magister Scientiae em Ciência Florestal) - Universidade Federal de Viçosa, Minas Gerais.

SOFFER, M. L. A. P. Produção de polpa celulósica a partir de engaço de bananeira. 2001. Dissertação (Mestrado em Ciência e Tecnologia de Madeiras) - Universidade de São Paulo, Piracicaba.

SOUZA, D. T. De; ONOYAMA, M. M.; SANTOS, P. S. S. Celulose Proveniente de Fibras Alternativas: Uma Solução Viável. Agroenergia em Revista, v. 4, n. 9, p. 64-67, 2015. 
SUPERBIA, F. F.; PAULA, N. F. De. Utilização da palha de cana de açúcar para a produção de papel artesanal. Ciência \& Tecnologia: FATEC-JB, v.3, Suplemento. 2011.

TEIXEIRA, M. B. D.; OLIVEIRA, R. A.; GATTI, T. H.; SUAREZ, P. A. Z. O papel e suas Aplicações. Revista virtual de Química. No prelo.

VIDAL, A. C. F.; HORA, A. B. A indústria de papel e celulose. In.: BNDES. Banco Nacional de Desenvolvimento Econômico e Social. BNDES 60 anos - Perspectivas Setoriais. Rio de Janeiro, 2012.

VIEIRA, L, R. Percurso e Percalços Do Papel: Uma História de Evolução e Problemáticas de um Meio de Comunicação. Revista Brasileira de Arqueometria, Restauração e Conservação - ARC - Vol. 3 - Edição Especial. 2011. 